\title{
Comparison of prescriber evaluations and patient-directed self-reports in office-based practice for buprenorphine treatment of opiate-dependent individuals in France, 2002
}

\author{
Estelle Lavie' \\ Mélina Fatséas' \\ Jean-Pierre Daulouède ${ }^{1,2}$ \\ Cécile Denis' \\ Jacques Dubernet ${ }^{1}$ \\ Laurent Cattan ${ }^{3}$ \\ Marc Auriacombe' \\ 'Laboratoire de psychiatrie/EA4I39, \\ INSERM IFR-99 and Faculté de \\ médecine Victor Pachon, University \\ Victor Segalen Bordeaux 2, Bordeaux, \\ France; ${ }^{2}$ Bizia, Centre de soins \\ d'addictologie, Centre Hospitalier \\ de la Côte Basque, Bayonne, France; \\ ${ }^{3}$ Centre médical, Noisy-le-sec, France
}

Correspondence: Marc Auriacombe Centre Carreire du CHCP, 121 , rue de la Béchade, 33076 Bordeaux cedex - France Tel +33556561738

Fax +33556566703

Email marc.auriacombe@u-bordeaux2.fr

\begin{abstract}
The objective of this cross-sectional evaluation study was to compare data generated through prescriber assessments, and data generated from independent direct contact with opiate-dependent patients in office-based practice to evaluate buprenorphine treatment for modality of buprenorphine absorption, benzodiazepine use, and depressive symptoms. A group of buprenorphine office-based practice prescribers was selected to participate in this study. They were asked to screen for inclusion all their patients coming for a visit from February to August 2002. Once included by their prescribing physician, patients were given a series of self-administered questionnaires to be returned directly to the research staff, independently of their prescriber. Each prescriber was given a questionnaire to complete based on their knowledge and interview of the patient. Items assessed were history of current treatment, current substance use, buprenorphine treatment related behavior (daily frequency of intake, route of administration), benzodiazepine use and existence of a major depressive episode. Prescribers and patients' questionnaires were compared. Concordance of both assessments was assessed by kappa statistics. The sensitivity and specificity as well as the positive and negative predictive values of prescriber collected information were compared to that of their patients'. There was an overall good correlation between both data sources on the procedures for buprenorphine use especially for intravenous use of buprenorphine. There were important variations: obtaining buprenorphine without a prescription or with a prescription made by another doctor, intravenous administration of buprenorphine, use of benzodiazepines, and depression were underestimated by prescribers.
\end{abstract}

Keywords: addiction, opiates, concordance, validity, buprenorphine, general medicine

\section{Introduction}

Since medical doctors in France have been allowed to prescribe buprenorphine for the treatment of opiate-dependent patients, it is estimated that $20 \%$ of them have prescribed this medication (OFDT 2004). Most of them treat less than 5 patients simultaneously. Data from comparative clinical trials in the literature show that buprenorphine gives similar results to those of methadone (Mattick et al 2003; Gerra et al 2004) when controlling for dosage and induction issues. Numerous studies are now available (Auriacombe et al 2004; Fatseas and Auriacombe 2007) and several indicators report a positive impact of this treatment as it is provided in France (Vignau and Brunelle 1998; OFDT 2003; Costes et al 2004). These are either descriptive cross-sectional studies of patients receiving buprenorphine treatment (Bouchez and Vignau 1998; Vignau and Brunelle 1998; Damon et al 2001; Vignau et al 2001; Thirion et al 2002) or studies comparing patients at the initiation of buprenorphine treatment and several 
months later (De Ducla et al 2000; Duburcq et al 2000; Fhima et al 2001). Other studies, concerning in particular patients attending specialized addiction centers (Thirion et al 1999, 2001; Barrau et al 2001), or participating in syringe-exchange programs (Moatti et al 2001; Obadia et al 2001; Valenciano et al 2001) have reported the existence of inappropriate use of buprenorphine by the nasal or intravenous route, as well as "doctor-shopping" behavior. These reports of misuse are not in themselves a surprise and it was reasonable to expect them (Auriacombe 2005). As many untreated opiatedependent patients use their opiate of choice by the venous or nasal route, it was reasonable to expect to find a certain number of treated patients continuing to use these routes of administration.

The combination of buprenorphine with benzodiazepines is generally not recommended as it may lead to severe respiratory depression (VIDAL 2004). However, in practice, the use of benzodiazepines is very frequent in buprenorphine-treated patients (13\% to $47 \%$ of subjects) (OFDT 2004). Among these patients, benzodiazepines may be abused and lead to misuse (excess dosages, off-prescription use, etc).

In such a context, it is important to know if doctors managing buprenorphine-treated patients are capable of identifying these predictable problems, in order to provide an appropriate therapeutic response. This question is particularly important within the French context as most of the doctors concerned are not addiction specialists and have minimal training and limited experience.

In some studies, depression was reported as a possible risk factor for use by the intravenous route and sharing of drug-injection equipment among opiate-dependent patients (Metzger et al 1991a, 1991b; Bertorelle et al 2000; Carrieri et al 2003). This could be a risk factor for buprenorphine misuse especially because studies have shown that depression is frequently under-diagnosed by general practioners (Nabarro 1984; Rodin and Voshart 1986; Katon 1987; Schulberg and Burns 1988; Lepine 1994; Weissman et al 1996; Lepine et al 1997; Tylee et al 1999a, 1999b).

The objective of this study was to assess the degree of agreement in an office-based setting between the data directly generated by buprenorphine-treated patients and the doctors' knowledge and perceptions about these same patients on a number of predetermined variables. In addition to information concerning the modalities of buprenorphine treatment, combination with benzodiazepines and misuse practices, we also investigated the existence of depressive episodes. We checked the validity of the information collected from doctors and compared with that collected from patients.

\section{Methods}

\section{Study design}

This was a cross-sectional study of buprenorphine-treated patients and their prescribing doctors carried out in France from February to August 2002.

\section{Sampling procedure}

France was divided into 35 zones containing equivalent numbers of buprenorphine prescribers on the basis of buprenorphine sales in the indication of severe opiate dependence. One hundred general practitioners were randomly selected and solicited in each of these zones. After first receiving an information letter about the study, doctors were contacted by telephone until 20 doctors had been recruited per zone. Participating doctors were given the necessary instructions for the inclusion of patients and collection of information. Doctors were asked to include consecutively over a one month period all patients to whom they prescribed buprenorphine, however long was the history of treatment. They could include a maximum of 25 patients.

\section{Data collection procedure}

The doctors gave each participating patient an envelope containing an explanatory letter about the study, a consent form and an anonymous self-questionnaire to be filled out. The patient had to answer the questionnaire at home and return it in a pre-stamped addressed envelope provided for this purpose. For his part, the doctor had to fill in an anonymous questionnaire for each included patient. In order to fill in this questionnaire, the doctor had to base his/her responses on data in the patient's medical files and his/her own knowledge about each patient. Pairing of prescriber questionnaires with patient self-questionnaires was conducted $a$ posteriori from the order numbers. The doctor had to note on each questionnaire he filled out the number on the self-questionnaire given to the corresponding patient.

\section{Variables collected}

The following information was collected on the two questionnaires: sociodemographic variables (age, gender, source of income, place of residence), information about buprenorphine-treatment procedures, benzodiazepine use and the existence of depression. Information on buprenorphine usage investigated previous use before current treatment, the obtaining of buprenorphine during the last month from one or more other doctors, the intravenous or nasal use of buprenorphine currently or in the past, as well the use of buprenorphine in divided doses several times a day. 
Three variables were not collected in a strictly similar way with the two questionnaires. Concerning the splitting of the buprenorphine dose several times a day, the patient had to mention if he had divided the last dose of buprenorphine, whereas the doctor had to indicate the number of daily doses prescribed on the patient's last prescription. For benzodiazepine use during the last month, patients had to indicate if the benzodiazepines that he/she had taken during the last month were prescribed by the doctor who had given them the questionnaire, whereas doctors had to note if benzodiazepines had been prescribed to the patient during the last month, which did not necessarily mean that the patient had effectively taken them. Different collection procedures were used to detect the occurrence of a depressive episode during the last month. The patient had to answer the "depressive episode" section of the Mini International Neuropsychiatric Interview (MINI) questionnaire (Sheehan et al 1998). This questionnaire is a tool for establishing a clinical diagnosis according to the International Classification of Diseases 10th edition (ICD-10) (Organisation Mondiale de la Santé 1993) and the Diagnostic and Statistical Manual of mental disorders version IV of the American Psychiatric Association (DSM-IV) (APA 1996). For this study, the ICD-10 version of the MINI was used for self-rating. The doctor, on the other hand, had to report the absence, probable presence or effective presence of symptoms of depression in the patient during his usual clinical examination.

The understandability of the patient questionnaire was tested beforehand on ten volunteer patients, in the presence of an investigator. After filling in the questionnaire, the investigator made sure that each question had been perfectly understood and noted any of the patients' suggestions. This preliminary test showed an excellent understanding by patients. In addition, 49 patients answered the questionnaire in front of an independent investigator a few days after filling in the questionnaire on their own. No statistically significant difference was found between the patients' responses by these two self-reporting methods.

\section{Analysis strategy}

The doctors' responses were re-coded as variables with three levels: "yes", "no", “don't know". It should be noted that only the doctor had the opportunity of answering "don't know", whereas the patient had to answer all questions by either "yes" or "no". Missing data were coded "no answer".

A description of the data collected by doctors and patients was first made. The distribution of the variables was described by their frequencies.
Secondly, the degree of concordance between the doctors' and patients' responses was analysed by using the kappa statistic (Cohen 1960; Byrt et al 1993), for variables collected in a similar way with the two questionnaires. The value of kappa varies between -1 (total disagreement between the two responses), 0 (independence of responses) and +1 (total agreement between the two responses). Above 0.80 , concordance is considered to be excellent, between 0.61 and a 0.80 it is considered good, between 0.41 and a 0.60 moderate, between 0.21 and a 0.40 poor and below $0.21 \mathrm{bad}$ (Landis and Koch 1977). This analysis of concordance was not carried out for three variables, divided dose of buprenorphine, use of benzodiazepines and diagnosis of depression, since these were not collected in a similar way by the two questionnaires.

Finally we studied the validity of the doctors' responses in relation to those of the patients for all variables. For each doctor-patient pair we used the information provided by patients in their responses to the self-questionnaire as reference. The sensitivity and specificity of the doctors' responses were calculated. The sensitivity evaluated the capacity of the doctor to correctly detect patient practices. The sensitivity of the doctor's response for a given question was defined as the proportion of affirmative responses by doctors among all the affirmative responses of patients to the same question. The specificity evaluated the capacity of doctors to correctly detect patients who did not have the practices for which they were questioned. The specificity of the doctor's response for a given question was defined as the proportion of negative responses of the doctors among all the negative responses of the patients for the same question. We also calculated the positive and negative predictive values of the doctor's responses. The positive predictive value (PPV) represented, for a given practice, the proportion of patients who really presented this practice among the cases reported by the doctor. The PPV was defined as the probability that the patient gave an affirmative response when the doctor also gave an affirmative response. The negative predictive value (NPV) represented, for a given practice, the proportion of patients who did not present this practice among the cases that the doctor reported as not presenting it. The NPV was defined as the probability that the patient answered by a negative when the doctor also gave a negative response.

Statistical analysis of the whole database was first carried out by the Louis Harris Medical Institute, with COSI $4.11^{\circledR}$ software (MLI, France) and DAG Stat ${ }^{\circledR}$ software for measurements of Kappa (Mackinnon 2000). Validity analyses were conducted by the Laboratoire de Psychiatrie of the Université 
Victor Segalen Bordeaux 2, using the database provided by Louis Harris Medical Institute and SAS statistical software (version 8.2; SAS institute, Inc., Cary, NC, USA).

\section{Results}

A total of 460 doctors took part in the study. Doctors filled in 2547 questionnaires and 1289 self-questionnaires were sent back by the patients. Out of these 1289 self-questionnaires, 1172 could be matched with a doctor questionnaire. This was because doctors did not return the questionnaire corresponding to the patients whom they included for 117 patient questionnaires. We compared the doctor questionnaires of patients who returned the self-questionnaire $(n=1172)$ with those of the patients who did not return the self-questionnaire $(n=1375)$, on the basis of general characteristic (age, gender, dosage of buprenorphine, history of treatment, etc). This comparison showed that there was no significant difference between responding and nonresponding patients for those variables.

\section{Description of the sample and distribution of responses in each questionnaire}

Most of the patients were male $(72.9 \%)$. The average age was 33 years. More than half of the patients $(56.1 \%)$ had a regular or occasional salaried job, and $68.4 \%$ were tenants or owners of their home (Table 1).

Missing data ("no answer") were more frequent among patients than doctors (Table 2). The frequency of “don't know" responses by doctors ranged from 0 to a little more than $17 \%$ depending on the question. The most frequent doctor "don't knows" concerned (1) the use of buprenorphine without a prescription before the current medical treatment, (2) use of buprenorphine by the nasal route lifetime and during the past 30 days and (3) the prescription of buprenorphine by another doctor before current medical treatment.

With regard to the frequencies of affirmative responses, the doctors underestimated the practices declared by their patients for almost all variables. Two variables were exceptions however: prescription of buprenorphine by another doctor before the current treatment and prescription of benzodiazepines during the last month by the doctor prescribing the buprenorphine, which were over-estimated by doctors (Table 2).

\section{Analysis of the concordance of responses}

The questions for which there was a good agreement were: obtaining of buprenorphine without prescription during the
Table I General characteristics of subjects in the sample. Cross-sectional study of buprenorphine-treated patients and their prescribing doctors France, $2002(n=1172)$

\begin{tabular}{|c|c|c|}
\hline & $\mathbf{n}$ & $\%$ \\
\hline Men & 854 & 72.9 \\
\hline \multicolumn{3}{|l|}{ Age } \\
\hline$<25$ years. & 123 & 10.5 \\
\hline 25 to 29 years & 209 & 17.8 \\
\hline 30 to 34 years & 315 & 26.9 \\
\hline 35 to 39 years & 252 & 21.5 \\
\hline$\geq 40$ years & 191 & 16.3 \\
\hline $\mathrm{NA}^{\prime}$ & 82 & 7.0 \\
\hline \multicolumn{3}{|l|}{ Source of income ${ }^{2}$} \\
\hline Regular salary & 517 & 44.1 \\
\hline Occasional salaried work & 141 & 12.0 \\
\hline Moonlighting (nondeclared work) & 77 & 6.6 \\
\hline Minimum income allocation (RMI) & 282 & 24.1 \\
\hline Unemployment benefit & 135 & 11.5 \\
\hline Sickness/disability allowance & 66 & 5.6 \\
\hline None & 13 & I.I \\
\hline Other & 67 & 5.7 \\
\hline NA & 28 & 2.4 \\
\hline \multicolumn{3}{|l|}{ Place of residence } \\
\hline Owner or tenant & 802 & 68.4 \\
\hline Parents & 239 & 20.4 \\
\hline Friends & 36 & 3.1 \\
\hline Hotel & 12 & 1.0 \\
\hline Squat & 16 & 1.4 \\
\hline Other & 41 & 3.5 \\
\hline NA & 26 & 2.2 \\
\hline
\end{tabular}

Notes: 'No answer; ${ }^{2}$ Several possible answers.

last month, obtaining of buprenorphine prescribed by another doctor during the last month, intravenous use of buprenorphine during the last month (Table 3). The questions for which there was a moderate agreement were: prescription of buprenorphine by another doctor before treatment by the current doctor, life-time intravenous use of buprenorphine, use of buprenorphine by the nasal route during the last month, use of buprenorphine without prescription before treatment by the current doctor. Finally the question for which there was a poor agreement was life-time use of buprenorphine by the nasal route (Table 3).

\section{Sensitivity and specificity of the doctors' responses}

The two questions for which the sensitivities of the doctors' responses were the highest $(80.5 \%$ and $73.6 \%$, respectively) 
Table 2 Description of data obtained from doctors and reported by the patients in the self-questionnaire. Cross-sectional study of buprenorphine-treated patients and their prescribing doctors France, $2002(\mathrm{n}=1172)$

\begin{tabular}{|c|c|c|c|c|c|}
\hline & & \multicolumn{2}{|c|}{ Patient } & \multicolumn{2}{|c|}{ Doctor } \\
\hline & & $\mathrm{n}$ & $\%$ & $\mathbf{n}$ & $\%$ \\
\hline Prescription of buprenorphine & No & 693 & 59.1 & 586 & 50.0 \\
\hline by another doctor before & Yes & 453 & 38.7 & 495 & 42.2 \\
\hline \multirow[t]{2}{*}{ treatment by current doctor } & $N^{\prime}$ & 26 & 2.2 & 7 & 0.6 \\
\hline & $\mathrm{DK}^{2}$ & - & - & 84 & 7.2 \\
\hline Took buprenorphine without & No & 710 & 60.6 & 565 & 48.2 \\
\hline \multirow[t]{3}{*}{ prescription before current doctor } & Yes & 432 & 36.9 & 369 & 31.5 \\
\hline & NA & 30 & 2.6 & 35 & 3.0 \\
\hline & DK & - & - & 203 & 17.3 \\
\hline Obtained buprenorphine by & No & 951 & 81.1 & 1021 & 87.1 \\
\hline \multirow[t]{3}{*}{ co-prescription during last month } & Yes & 206 & 17.6 & 103 & 8.8 \\
\hline & NA & 15 & 1.3 & 36 & 3.1 \\
\hline & DK & - & - & 12 & 1.0 \\
\hline Obtained buprenorphine without & No & 980 & 83.6 & 1042 & 88.9 \\
\hline \multirow[t]{3}{*}{ prescription during last month } & Yes & 170 & 14.5 & 89 & 7.6 \\
\hline & NA & 22 & 1.9 & 3 & 0.3 \\
\hline & DK & - & - & 38 & 3.2 \\
\hline Life-time intravenous injection & No & 664 & 56.6 & 696 & 59.4 \\
\hline \multirow[t]{3}{*}{ of buprenorphine } & Yes & 491 & 41.9 & 409 & 34.9 \\
\hline & NA & 17 & 1.5 & 4 & 0.3 \\
\hline & DK & - & - & 63 & 5.4 \\
\hline Intravenous injection of & No & 937 & 79.9 & 990 & 84.5 \\
\hline \multirow[t]{3}{*}{ buprenorphine during last month } & Yes & 190 & 16.2 & 139 & 11.9 \\
\hline & NA & 45 & 3.8 & 8 & 0.7 \\
\hline & DK & - & - & 35 & 3.0 \\
\hline Life-time use of buprenorphine & No & 631 & 53.8 & 751 & 64.1 \\
\hline \multirow[t]{3}{*}{ by the nasal route } & Yes & 522 & 44.5 & 306 & 26.1 \\
\hline & NA & 19 & 1.6 & 0 & 0.0 \\
\hline & DK & - & - & 115 & 9.8 \\
\hline Use of buprenorphine by nasal route & No & 921 & 78.6 & 959 & 81.8 \\
\hline \multirow[t]{3}{*}{ during last month } & Yes & 179 & 15.3 & 110 & 9.4 \\
\hline & NA & 72 & 6.1 & 7 & 0.6 \\
\hline & DK & - & - & 96 & 8.2 \\
\hline \multirow[t]{4}{*}{ Depression ${ }^{3}$} & No & 612 & 52.2 & 640 & 54.6 \\
\hline & Yes & 557 & 47.5 & 477 & 40.7 \\
\hline & NA & 3 & 0.3 & 55 & 4.7 \\
\hline & DK & - & - & 0 & 0.0 \\
\hline Prescription of benzodiazepines & No & 918 & 78.3 & 876 & 74.7 \\
\hline during last month by the doctor & Yes & 240 & 20.5 & 283 & 24.1 \\
\hline \multirow[t]{2}{*}{ prescribing buprenorphine } & NA & 14 & 1.2 & 13 & I.I \\
\hline & DK & - & - & 0 & 0.0 \\
\hline Obtained benzodiazepines from & No & 955 & 81.5 & 1010 & 86.2 \\
\hline another doctor or without & Yes & 203 & 17.3 & 87 & 7.4 \\
\hline \multirow[t]{2}{*}{ prescription during the last month } & NA & 14 & 1.2 & 14 & 1.2 \\
\hline & DK & - & - & 61 & 5.2 \\
\hline Buprenorphine taken in splitted & No & 554 & 47.3 & 834 & 71.2 \\
\hline \multirow[t]{3}{*}{ doses during the day ${ }^{4}$} & Yes & 590 & 50.3 & 331 & 28.2 \\
\hline & NA & 28 & 2.4 & 7 & 0.6 \\
\hline & DK & - & - & 0 & 0.0 \\
\hline
\end{tabular}

Notes: 'No answer = missing data; ${ }^{2}$ Answered "don't know"; "Yes" doctors = "yes + probable"; ${ }^{4}$ Last splitted dose for the patient vs splitted doses prescribed by doctor. 
Table 3 Agreement between doctors' responses and the information reported by patients on self-questionnaires. Cross-sectional study of buprenorphine-treated patients and their prescribing doctors France, $2002(n=1172)$

\begin{tabular}{lll}
\hline & Kappa & $\begin{array}{l}\text { Proportion } \\
\text { of concordant } \\
\text { results \% }\end{array}$ \\
\hline $\begin{array}{l}\text { Obtained buprenorphine without } \\
\text { prescription during last month } \\
\text { Obtained buprenorphine by } \\
\text { co-prescription during last month }\end{array}$ & 0.69 & 84 \\
$\begin{array}{l}\text { Intravenous injection of buprenorphine } \\
\text { during last month }\end{array}$ & 0.61 & 81 \\
$\begin{array}{l}\text { Prescription of buprenorphine by } \\
\text { another doctor before treatment by } \\
\text { current doctor }\end{array}$ & 0.57 & 78 \\
$\begin{array}{l}\text { Life-time intravenous injection } \\
\text { of buprenorphine }\end{array}$ & 0.56 & 78 \\
$\begin{array}{l}\text { Use of buprenorphine by nasal } \\
\text { route during last month }\end{array}$ & 0.56 & 78 \\
$\begin{array}{l}\text { Administration of buprenorphine } \\
\text { without prescription before current } \\
\text { doctor' }\end{array}$ & 0.42 & 71 \\
$\begin{array}{l}\text { Life-time use of buprenorphine } \\
\text { by nasal route }\end{array}$ & 0.38 & 69 \\
\hline
\end{tabular}

Note: 'Among patients who have already taken buprenorphine in the past.

were prescription of buprenorphine by another doctor before the current treatment and prescription of benzodiazepines by the doctor who provided the questionnaire during the last month (Table 4).

The specificity of the doctors' responses was higher than $67 \%$ for all the questions. The two questions with the highest specificities were intravenous injection of buprenorphine during the last month and use of buprenorphine without prescription during the last month $(95.2 \%$ and $94.8 \%$, respectively).

Three behaviors were misidentified by doctors (sensitivity lower than 30\%): obtaining buprenorphine by co-prescription during the last month (reported by $17.6 \%$ of patients), obtaining buprenorphine without prescription during the last month (reported by $14.5 \%$ of the patients) and use of buprenorphine by the nasal route during the last month (reported by $15.3 \%$ of the patients) (Tables 2 and 4).

The sensitivity of doctors for detection of a depressive disorder was poor, even when probable cases were re-rated as confirmed cases (Table 4). Only a little more than half of the patients $(52.5 \%)$ detected as having a "probable" depressive disorder by the doctor really presented a depressive episode according to the MINI. More important, 39.3\% of patients not presenting a depressive disorder according to the doctor fulfilled the MINI criteria of a depressive episode (Table 5).

\section{Predictive values of the doctors' responses}

The variables with the highest PPV were splitting of buprenorphine doses during the day, prescription of buprenorphine by another doctor before the current treatment and use of buprenorphine without a prescription before the current treatment (Table 4). The variables with the highest NPV were prescription of benzodiazepines during the last month by the doctor who provided the questionnaire, obtaining of buprenorphine without prescription during the last month and nasal use of buprenorphine during the last month.

\section{Discussion}

The objective of this study was to assess the level of concordance between the information collected directly from buprenorphine treated patients and the knowledge and perceptions of doctors about the procedures for use of buprenorphine, benzodiazepine use and the existence of a depressive disorder. Our study sample included 1172 doctorpatient pairs. The results showed that there was an overall satisfactory concordance between the responses provided by patients and doctors on the procedures for buprenorphine use. However, some behaviors of a minority of patients did not seem to be correctly identified by the doctors.

Less than half the patients included by the doctors returned the questionnaire. The general characteristics of responder patients did not differ significantly from those of nonresponders. However, although the response rate of patients was satisfactory (approximately 50\%), the high proportion of nonresponders may have biased the concordance results. For instance, patients who did not respond to the questionnaire may have been less involved in their treatment so that their doctor had a less good knowledge of their practices. This selection bias may have led to an overestimation of the concordance between the doctors' and patients' responses. Likewise, approximately two thirds of doctors solicited took part in the study. We have no information about the reasons why doctors failed to participate. However, this did not seem to be due to a refusal since the 700 solicited doctors (20 per zone) had initially accepted to take part. It may be that certain doctors lacked the time or motivation to return the questionnaires. As for the patients, the study could have excluded doctors who were less involved in the management of buprenorphine-treated patients. 
Table 4 Validity of the doctors' responses compared to data in patient self-questionnaires. Cross-sectional study of buprenorphine-treated patients and their prescribing doctors France, 2002 ( $n=1172$ )

\begin{tabular}{|c|c|c|c|c|c|}
\hline & $\begin{array}{l}\text { Sensitivity } \\
\%\end{array}$ & $\begin{array}{l}\text { Specificity } \\
\%\end{array}$ & $\begin{array}{l}\text { PPV' } \\
\%\end{array}$ & $\begin{array}{l}\mathbf{N P V}^{2} \\
\%\end{array}$ & $\mathbf{n}$ \\
\hline $\begin{array}{l}\text { Prescription of buprenorphine by another } \\
\text { doctor before treatment by current doctor }\end{array}$ & 80.5 & 74.5 & 84.3 & 69.3 & 677 \\
\hline $\begin{array}{l}\text { Administration of buprenorphine without } \\
\text { prescription before current doctor }{ }^{3}\end{array}$ & 68.5 & 74.9 & 80.3 & 61.3 & 577 \\
\hline $\begin{array}{l}\text { Obtained buprenorphine by co-prescription } \\
\text { during last month }\end{array}$ & 22.6 & 93.6 & 43.7 & 84.7 & 1109 \\
\hline $\begin{array}{l}\text { Obtained buprenorphine without } \\
\text { prescription during last month }\end{array}$ & 23.8 & 94.8 & 44.3 & 87.8 & 1110 \\
\hline Life-time intravenous injection of buprenorphine & 67.8 & 85.6 & 77.8 & 78.2 & 1088 \\
\hline $\begin{array}{l}\text { Intravenous injection of buprenorphine } \\
\text { during last month }\end{array}$ & 51.6 & 95.2 & 77.7 & 78.2 & 1088 \\
\hline Life-time use of buprenorphine by nasal route & 47.7 & 86.3 & 74.2 & 66.7 & 1040 \\
\hline $\begin{array}{l}\text { Use of buprenorphine by nasal route } \\
\text { during last month }\end{array}$ & 29.6 & 93.1 & 45.3 & 87.3 & 1004 \\
\hline \multicolumn{6}{|l|}{ Depression ${ }^{4}$} \\
\hline "Probables" classed "yes" & 53.1 & 67.0 & 59.8 & 60.7 & 1114 \\
\hline "Probables"classed "no" & 29.5 & 86.7 & 67.2 & 57.1 & 1114 \\
\hline "Probables" excluded & 38.6 & 83.4 & 67.2 & 60.7 & 874 \\
\hline $\begin{array}{l}\text { Prescription of benzodiazepines during the last } \\
\text { month by the doctor prescribing buprenorphine }\end{array}$ & 73.6 & 88.9 & 63.5 & 92.7 & 1145 \\
\hline $\begin{array}{l}\text { Buprenorphine taken in splitted doses } \\
\text { during the day }\end{array}$ & 46.9 & 91.8 & 85.9 & 61.9 & 1137 \\
\hline
\end{tabular}

Notes: 'Positive predictive value; ${ }^{2}$ Negative predictive value; ${ }^{3} \mathrm{Among}$ patients who already took buprenorphine in the past; ${ }^{4}$ See Table 5 for details.

Perhaps these doctors lacked information about their patients and this would also have resulted in an over-estimation of the agreement between the doctors' and patients' responses in our sample.

In our study, we chose to test the sensitivity and specificity of the information collected by the doctors compared to the information given by patients. We therefore made the hypothesis that patients provide more accurate responses when they respond independently from their prescribing doctor. Patients may hide certain forms of misuse from their doctor in order to meet expectations, and therefore avoid the risk that doctors change their treatment.

The sensitivity of doctors to detect a depressive disorder identified by the MINI was bad. Even in the best case for a high sensitivity (when probable cases were considered to present a depressive disorder), the doctors only detected slightly more than one depressive patient out of two. The MINI alone cannot confirm a valid diagnosis of depression. Some authors have underlined the potential discrepancy between what the MINI questionnaire measures and a diagnosis of depression established by a psychiatrist (Duburcq et al 1999). In particular, the specificity of the
MINI questionnaire is not very good so that it will tend to over-estimate the prevalence of depressive disorders.

It is possible, however, that doctors underestimate the incidence of depressive disorders among dependent patients, as they do with their other patients. Studies have shown that in the general population, a large number of depressive disorders were not detected by general practitioners (Nabarro 1984; Rodin and Voshart 1986; Katon 1987; Schulberg and Burns 1988; Lepine 1994; Weissman et al 1996; Lepine et al 1997; Tylee et al 1999a, 1999b). Finally, depressive disorders may change over time and may not be detected at a given time. These results must encourage doctors to better evaluate and more systematically seek the existence of depressive disorders in their patients.

The questions about buprenorphine administration during the last month (obtaining buprenorphine without a prescription or with a prescription made by another doctor and intravenous administration) had a good concordance. However, the sensitivity of the doctors' responses about these practices was poor. This shows that the doctors misidentified patients who get buprenorphine by other means than their prescription, just as they only detect one out of two patients who 
Table 5 Depressive episodes among patients during the last month. Comparison of self-rating with MINI and doctor's evaluation. Cross-sectional study of buprenorphine-treated patients and their prescribing doctors France, $2002(n=1114 *)$

\begin{tabular}{lllllll}
\hline \multirow{2}{*}{ Doctor } & \multicolumn{3}{l}{ Patient evaluation with MINI } \\
\cline { 2 - 7 } & \multicolumn{2}{l}{ Total } & \multicolumn{3}{c}{ Depressive } & \multicolumn{2}{c}{ Nondepressive } \\
\cline { 2 - 7 } & $\mathbf{n}$ & $\%$ & $\mathbf{n}$ & $\%$ & $\mathbf{n}$ & $\%$ \\
\hline Yes & 235 & 100 & 158 & 67.2 & 77 & 32.8 \\
No & 639 & 100 & 251 & 39.3 & 388 & 60.7 \\
Probable & 240 & 100 & 126 & 52.5 & 114 & 47.5 \\
Total & 1114 & 100 & 535 & 48.0 & 579 & 52.0 \\
\hline
\end{tabular}

Note: *Exclusion of missing data and "don't knows".

inject buprenorphine. Patients concerned by these practices may have a tendency to hide it from their doctor, even when interviewed by him/her. On the contrary, the specificity concerning these questions was very good. This means that the doctor knew when patients were not concerned by these practices. Most of the patients in the sample were not concerned with these practices since only approximately one third of the subjects were involved each time. This probably explains the good concordance observed as the calculation of kappa takes into account the concordance for positive responses and also for negative responses. Here, it is the good agreement between the patients' and doctors' negative responses that influenced the total concordance.

Another practice that was largely underestimated by the doctors was the use of buprenorphine by the nasal route. Moreover, many doctors were unable to say if their patients used this route of administration, as the number of "don't knows" was one of the highest. However, the administration of buprenorphine by the nasal route concerned close to one patient out of six in our sample. This practice is seldom documented in studies on buprenorphine treatment unlike the intravenous use of buprenorphine. This lack of information may explain why the doctors do not think about questioning their patients on this subject. It is also possible that this is a more recent modality of buprenorphine use. It is important to make health professionals aware of this practice. Doctors must discuss this question with their patients and inform them about the necessary conditions for treatment efficacy and the risks of misuse.

The use of benzodiazepines without a prescription seemed to be underestimated by the doctors, either because they did not sufficiently question their patients about this point, or because the patients preferred to hide this use. However, no calculation of concordance or sensitivity/specificity could be conducted on this variable, as the questions were not formulated to permit this.

There was one very surprising result. Almost one third of the doctors in this study stated that they prescribed a splitting of daily dosing for buprenorphine whereas all recommendations state that buprenorphine must be given in a single daily dose or even once every two days. This is clearly stated in the French Summary of Product Characteristics in the Vidal ${ }^{\circledR}$ dictionary (VIDAL 2004) and all other European, American, and Australian buprenorphine treatment recommendations to doctors. Of notice, similar results were obtained in 1996 in a follow-up study of patients treated by buprenorphine in France from healthcare networks (De Ducla et al 2000). Data in that study were collected retrospectively from general practitioners. Approximately one third of doctors declared that they prescribed splitting of daily dosage of buprenorphine to their patients even after induction and stabilization. At the time, this was considered to be related to lack of knowledge and experience. According to authors, this practice resulted from an unjustified fear that the duration of action of buprenorphine is less than 24 hours due to its short half-life. In some French language publications on buprenorphine treatment, the term "splitting of dispensing" (fractionnement in French), is used, wrongly, in lieu of "daily dispensing" which is recommended at the start of treatment, versus "weekly dispensing". This misuse of language may cause confusion and suggest that splitting of the daily buprenorphine dose is recommended at the start of treatment. It should be underlined that a single daily dose is important to obtain a lasting and optimal effect that is essential for treatment efficiency.

To conclude, the analysis of the concordance between the information collected by doctors and self-questionnaires filled in by patients shows that overall doctors have satisfactory information about how their patients use buprenorphine. The results also showed however that doctors missed those few patients that used buprenorphine intranasaly, off-prescription use of benzodiazepines and depressive disorders. Finally, it was found that nearly one third of the doctors prescribed buprenorphine using a splitting of daily dosing contrary to all recommendations. The doctors recruited for this study were general practitioners in office-based practice. It would be of interest to know if the concordance would have been better if addiction specialist doctors in treatment centers were questioned. It would be interesting to conduct the same study with doctors practicing in specialized addiction treatment centers to fully understand the significance and complete implications of the results of this study. 
From a clinical and treatment perspective, the results of this study show that doctors prescribing buprenorphine may have a good knowledge of their patient's behavior regarding their treatment. They lack a good detection of depression, but this would seem to be a general characteristic of doctors in general practice and not specific to buprenorphine prescribers or related patients.

From the perspective of research, this study stresses on the importance of avoiding to collect data about patients from their treating doctors and possibly other related staff and to prefer specific research interviews in studies that have as an objective to evaluate patient behavior in treatment settings.

\section{Acknowledgments}

The authors would like to warmly thank all the patients and doctors who agreed to take part in this study. An independent scientific committee (Dr L Cattan, Dr J-P Daulouède) and The Louis Harris Medical Institute (Dr A Finois), determined the study's methods, carried out its implementation, the data collection, constitution of the database and first statistical analyses through a research grant from Schering-Plough France. The Laboratoire de psychiatrie at Université Victor Segalen Bordeaux 2 carried out further analyses, interpretation of the results and the writing of this manuscript through its own funding.

\section{References}

[APA] American Psychiatric Association. 1996. [DSM-IV Manuel Diagnostique et Statistique des Troubles mentaux, $4^{\mathrm{e}}$ édition. (Version Internationale, Washington DC, 1995)]. Paris, MASSON.

Auriacombe M. 2005. [Quoi de neuf pour le traitement de la dépendance aux opiacés en France? Quelques spéculations. Médecine et addictions. Peut-on intervenir de façon précoce et efficace?] Reynaud M, Bailly D, Venisse J (ed), Collection Médecine et Psychothérapie: pp. 207-12.

Auriacombe M, Fatseas M, Dubernet J, et al. 2004. French field experience with buprenorphine. Am J Addict, 13(Suppl 1):S17-28.

Barrau K, Thirion X, Micallef J, et al. 2001. Comparison of methadone and high dosage buprenorphine users in French care centres. Addiction, 96:1433-41.

Bertorelle V, Auriacombe M, Grabot D, et al. 2000. [Evaluation quantitative des pratiques de partage de matériel à risque de contamination infectieuse virale chez les usagers d'opiacés par voie intraveineuse faisant une demande de soins - utilisation de l'autoquestionnaire RAB]. Encephale, 26:3-7.

Bouchez J, Vignau J. 1998. The French experience - the pharmacist, general practitioner and patient perspective. Eur Addict Res, 4(Suppl 1):19-23.

Byrt T, Bishop J, Carlin JB. 1993. Bias, prevalence and kappa. J Clin Epidemiol, 46:423-9.

Carrieri MP, Rey D, Loundou A, et al. 2003. Evaluation of buprenorphine maintenance treatment in a French cohort of HIV-infected injecting drug users. Drug Alcohol Depend, 72:13-21.

Cohen J. 1960. A coefficient of agreement for nominal scales. Educ Psychol Meas, 20:27-46.
Costes JM, Cadet-Taïrou A, Thirion X, et al. 2004. [Du point de vue de la santé publique, quels sont les résultats positifs que l'on peut attribuer aux traitements de substitution aux opiacés en termes de prise en charge médicale, psychologique et sociale, des usagers et quels sont leurs effets défavorables ou non souhaités (mésusage...)?] Alcoologie et Addictologie, 26(4 Suppl):38S-54S.

Damon M, Claroux-Bellocq D, Degré A. 2001. [Traitement de substitution par la buprénorphine-haut-dosage en médecine de ville en Aquitaine.] Revue Médicale de l'Assurance Maladie, 32:311-8.

De Ducla M, Gagnon A, Mucchielli A, et al. 2000. [Suivi de patients pharmacodépendants aux opiacés traités par buprénorphine haut dosage à partir de réseaux de soins]. Annales de Médecine Interne, 151(Suppl A):A27-32.

Duburcq A, Blin P, Charpak Y, et al. 1999. [Utilisation d'un entretien diagnostique structuré pour identifier les épisodes dépressifs dans une étude épidémiologique: validation interne a posteriori]. Rev Epidemiol Sante Publique, 47:455-63.

Duburcq A, Charpak Y, Blin P, et al. 2000. [Suivi à deux ans d'une cohorte de patients sous buprénorphine haut dosage. Résultats de l'étude SPESUD (Suivi Pharmaco-Epidémiologique de Subutex en milieu de ville)]. Rev Epidemiol Sante Publique, 48:363-73.

Fatseas M, Auriacombe M. 2007. Why buprenorphine is so successful in treating opiate addiction in France. Curr Psychiatry Rep, 9:358-64.

Fhima A, Henrion R, Lowenstein W, et al. 2001. [Suivi à deux ans d'une cohorte de patients dépendants aux opiacés traités par buprénorphine haut dosage (Subutex)]. Ann Med Interne (Paris), 152(Suppl 3):IS26-36.

Gerra G, Borella F, Zaimovic A, et al. 2004. Buprenorphine versus methadone for opioid dependence: predictor variables for treatment outcome. Drug Alcohol Depend, 75:37-45.

Katon W. 1987. The epidemiology of depression in medical care. Int $J$ Psychiatry Med, 17:93-112.

Landis JR, Koch GG. 1977. The measurement of observer agreement for categorical data. Biometrics, 33:159-74.

Lepine JP. 1994. [Comorbidité des troubles anxieux et dépressifs: perspectives épidémiologiques]. Encephale, 20(Spec No 4):683-92.

Lepine JP, Gastpar M, Mendlewicz J, et al. 1997. Depression in the community: the first pan-European study DEPRES (Depression Research in European Society). Int Clin Psychopharmacol, 12:19-29.

Mackinnon A. 2000. A spreadsheet for the calculation of comprehensive statistics for the assessment of diagnostic tests and inter-rater agreement. Comput Biol Med, 30:127-34.

Mattick RP, Kimber J, Breen C, et al. 2003. Buprenorphine maintenance versus placebo or methadone maintenance for opioid dependence. Cochrane Database Syst Rev, 2:CD002207.

Metzger D, Woody G, De Philippis D, et al. 1991a. Risk factors for needle sharing among methadone-treated patients. Am J Psychiatry, 148:636-40.

Metzger DS, Woody GE, Druley P, et al. 1991b. Psychiatric symptoms, high risk behaviors and HIV positivity among methadone patients. NIDA Res Monogr, 105:490-1.

Moatti JP, Vlahov D, Feroni I, et al. 2001. Multiple access to sterile syringes for injection drug users: vending machines, needle exchange programs and legal pharmacy sales in Marseille, France. Eur Addict Res, 7:40-5.

Nabarro J. 1984. Unrecognised psychiatric illness in medical patients. Br Med J (Clin Res Ed), 289:635-6.

Obadia Y, Perrin V, Feroni I, et al. 2001. Injecting misuse of buprenorphine among French drug users. Addiction, 96:267-72.

[OFDT] Observatoire français des drogues et des toxicomanies. 2003. [Substitution aux opiacés en France, synthèse des informations disponibles de 1996 à 2001 en France.] Accessed on October 8, 2008. URL: http://www.ofdt.fr.

[OFDT] Observatoire français des drogues et des toxicomanies. 2004. [Les traitements de substitution en France : résultats récents 2004. Tendance $\mathrm{n}^{\circ}$ 37, OFDT, 8p. Juin 2004]. Accessed on October 8, 2008. URL: http://www.ofdt.fr/BDD/publications/.

Organisation Mondiale de la Santé. 1993. Classification Internationale des Maladies. Dixième révision. Genève, MASSON. 
Rodin G, Voshart K. 1986. Depression in the medically ill: an overview. Am J Psychiatry, 143:696-705.

Schulberg HC, Burns BJ. 1988. Mental disorders in primary care: epidemiologic, diagnostic, and treatment research directions. Gen Hosp Psychiatry, 10:79-87.

Sheehan DV, Lecrubier Y, Sheehan KH, et al. 1998. The Mini-International Neuropsychiatric Interview (MINI): the development and validation of a structured diagnostic psychiatric interview for DSM-IV and ICD-10. $J$ Clin Psychiatry, 59(Suppl 20):22-33; quiz 34-57.

Thirion X, Lapierre V, Micallef J, et al. 2002. Buprenorphine prescription by general practitioners in a French region. Drug Alcohol Depend, 65:197-204

Thirion X, Micallef J, Barrau K, et al. 2001. Recent evolution in opiate dependence in France during generalisation of maintenance treatments. Drug Alcohol Depend, 61:281-5.

Thirion X, Micallef J, Guet F, et al. 1999. [Dépendance aux psychotropes et traitements de substitution: tendances récentes. A propos de l'enquête OPPIDUM des centres d'Evaluation et d'Information sur les Pharmacodépendances (CEIP) d'octobre 1997]. Therapie, 54:243-9.

Tylee A, Gastpar M, Lepine JP, et al. 1999a. DEPRES II (Depression Research in European Society II): a patient survey of the symptoms, disability and current management of depression in the community. DEPRES Steering Committee. Int Clin Psychopharmacol, 14:139-51.
Tylee A, Gastpar M, Lepine JP, et al. 1999b. Identification of depressed patient types in the community and their treatment needs: findings from the DEPRES II (Depression Research in European Society II) survey. DEPRES Steering Committee. Int Clin Psychopharmacol, 14:153-65.

Valenciano M, Emmanuelli J, Lert F. 2001. Unsafe injecting practices among attendees of syringe exchange programmes in France. Addiction, 96:597-606.

VIDAL. 2004. [Dictionnaire VIDAL 2004]. Accessed on October 8, 2008. URL: http://www.vidalpro.net/medicaments/.

Vignau J, Brunelle E. 1998. Differences between general practitioner - and addiction centre - prescribed buprenorphine substitution therapy in France. Eur Addict Res, 4(Suppl 1):24-8.

Vignau J, Duhamel A, Catteau J, et al. 2001. Practice-based buprenorphine maintenance treatment (BMT): how do French healthcare providers manage the opiate-addicted patients? J Subst Abuse Treat, 21:135-44.

Weissman MM, Bland RC, Canino GJ, et al. 1996. Cross-national epidemiology of major depression and bipolar disorder. JAMA, 276:293-9. 